Pak. j. sci. ind. res. Ser. A: phys. sci. 2019 62A(2) 92-97

\title{
Comparative Study of Antimicrobial and Staining Activity of Selected Anthraquinone Dyes
}

\author{
Olufunmilayo Adeola Ajayi ${ }^{a *}$ and Gabriel Ademola Olatunji ${ }^{\mathrm{b}}$ \\ ${ }^{a}$ Department of Chemical Sciences, Faculty of Science, Crown-Hill University, P.M.B. 1605, \\ Eiyenkorin, Ilorin, Nigeria \\ ${ }^{\mathrm{b}}$ Department of Industrial Chemistry, Faculty of Physical Sciences, \\ University of Ilorin, P.M.B 1515, Ilorin, Nigeria
}

(received April 9, 2018; revised November 20, 2018; accepted November 29, 2018)

\begin{abstract}
The staining activity of twelve (12) anthraquinone dye derivatives was carried out to investigate the potential of the compounds as staining agents. The reactions of the compounds on organism cell walls were determined, and a comparison was drawn between the mechanism of action of the compounds against established mechanism of reaction of standard dyes used in biological staining. These compounds are BRAM/acetylated PPD, BRAM/PAP/p-TsCl, BRAM/Biaryl/PAP and BRAM/BzCl/PAP, BRAM/aniline, BRAM/o-toluidine, BRAM/p-toluidine, BRAM/m-toluidine, BRAM/p-anisidine, BRAM/m-anisidine, $\mathrm{BRAM} / \mathrm{PAP}$, and BRAM/p-iodoaniline. The antibacterial and antifungal activity of these compounds was determined. BRAM/BzCl/PAP exhibited higher biological activity on the bacterial types than most of the controls. From the results of the antifungal test, BRAM/m-toluidine and BRAM/acetylated PPD indicated very significant activity as much as the controls. The staining tests carried out on the compounds show that they are viable alternatives to existing dyes currently used in bacterial and fungal identification.
\end{abstract}

Keywords: antibiotics, staining activity, anthraquinone dye

\section{Introduction}

Dyes can generally be described as coloured substances that have affinity to the substrate to which they are applied. They are used to impart colour to a substrate from a solution or fine dispersion (Booth, 2000). One obvious quality of dyes which cannot be ignored is colour. Dyes have been applied in various industries. In particular, anthraquinone dyes have been associated with dyeing of silk and wool. Dye classifications are made according to their usage in the dyeing process but they can also be broadly classified into natural and synthetic dyes. While natural dyes are of less significance to the dye chemist, several modifications have produced synthetic dyes like the reactive and the anthraquinone family which have several applications in the textile, food and drink industries.

In India, more than 450 plants have been identified that can be used as dyes in addition to having medicinal value (Chengaiah et al., 1997). Many of the plants used for dye extractions have also been classified as medicinal and possessing antimicrobial activity (Hussein et al., 1997). Latter studies on the nest of swallows had indicated that coloured feathers used to protect the eggs

*Author for correspondence; E-mail: tessynchrist@yahoo.com exhibited different antimicrobial properties as the colours varied (Peralta-Sánchez et al., 2013).

In this study, the staining capabilities of anthraquinone dye derivatives were tested and comparisons made with standard dyes already in use. Investigating antimicrobial activity of the compounds and their staining capabilities provided an irresistible opportunity to analyze the possibility of a relationship between colour and inhibitory activity. Synthesis, characterization and antibacterial activity of seven of the twelve compounds have been reported in an earlier study (Ajayi and Olatunji, 2016). These seven derivatives include BRAM/aniline, BRAM/o-toluidine, BRAM/p-toluidine, BRAM/mtoluidine, $\mathrm{BRAM} / \mathrm{p}$-anisidine, $\mathrm{BRAM} / \mathrm{m}$ - anisidine, BRAM/PAP and BRAM/p-iodoaniline. The aim of this research is to investigate the staining capability of the anthraquinone derivatives which also have antimicrobial activity and determine their usefulness as alternatives to already existing commercial dyes. The staining capability of the derived compounds was tested on two genera of gram positive bacteria namely Staphylococcus aureus and Micrococcus luteus; three genera of gram negative bacteria which are Bacillus cereus, Escherichia coli and Pseudomonas aeruginosa; two genera of yeast namely Saccharomyces cerevisiae and Candida stellata; 
and two genera of fungi namely Saccharomyces cerevisiae and Candida stellata. The derived compounds were used to replace standard dyes as staining agents.

\section{Materials and Methods}

Melting point of the derivatives. All the compounds were melted at $>360^{\circ} \mathrm{C}$. This agrees with the findings of Baqi et al. (2008).

Antibacterial assay. The Kirby-Bauer test for antibiotic susceptibility, called the disc diffusion test was used to determine the antibacterial activity of the compounds (Bauer et al., 1966). The media used were nutrient media, Mueller Hinton agar and Salmonella shigella agar (SS agar). Molten agar $(20 \mathrm{~mL})$ was dispensed into sterile disposable petri dish containing $1 \mathrm{~mL}$ of $18 \mathrm{~h}$ broth of the organism mixed together (pour plate method) at $50{ }^{\circ} \mathrm{C}$ and allowed to set (Derwich et al., 2010, Iscan et al., 2002). Sterile cork borer of $4 \mathrm{~mm}$ diameter was sterilized using naked flame. This was carefully used to bore holes into the agar (Cheesbrough, 2004). $0.4 \mathrm{~mL}$ of each compound was put into its own labelled hole using calibrated hand micropipette. The organism-agarcompound plates (Petri dishes) were carefully packed into an incubator and incubated for $24 \mathrm{~h}$ at $37^{\circ} \mathrm{C}$. The diameter of zones of inhibition on the organisms by the compounds was measured in millimetres.

Antifungal assay. Standard procedure was adopted (Cheesbrough, 2004) for antifungal assay. Tests were carried out on Trichoderma viride ATCC 32630, Aspergillus flavus ATCC 9643, Aspergillus niger ATCC 6275, Fusarium oxysporium ATCC 48112 and Fusarium compacticum ATCC 201181. The fungal types were allowed to grow on a potato dextrose agar at $25^{\circ} \mathrm{C}$ until they sporulated. The fungal spores were harvested after sporulation by pouring a mixture of sterile glycerol and distilled water to the surface of the plate. Sterile cork borer of $4 \mathrm{~mm}$ diameter was sterilized using naked flame and carefully used to bore holes into the agar. About $0.4 \mathrm{~mL}$ of each compound was put into its own labelled hole using calibrated hand micropipette. Miconazole and ketoconazole were used as controls. The fungal cultures were incubated at $27^{\circ} \mathrm{C}$ for 4 days. The presence of zones of inhibition around each of the wells after incubation was regarded as the presence of antifungal action while the absence of any measurable zone of inhibition was interpreted as absence of antifungal action. The effect of the compounds on the fungal types was compared with that of the standard reference drugs.
Gram staining procedures. $2.5 \%$ phenol, $1 \%$ crystal violet and $10 \%$ ethanol were mixed in distilled water. The organisms were heated to fix them and crystal violet applied. After incubation for $2 \mathrm{~min}$, the smear was rinsed for 5-10 sec in water bath. Iodine/potassium iodide solution was used to incubate for $2 \mathrm{~min}$ after which rinsing with water for another $5 \mathrm{sec}$.

The entire wet specimen was covered with safranin solution $(0.5 \%)$ and rinsed for $5 \mathrm{sec}$ with water after which all was covered and observed under the microscope.

Each of the derived compounds was used to replace crystal violet and safranin in turns and also observed.

Lactophenol cotton blue. 70\% alcohol was dropped on a clean slide. A stiff inoculating wire was used to remove excess material from fungi cultures after which the whole length of the wire was heated red hot and allowed to cool for $10 \mathrm{sec}$ and then placed in the cultures. The neck of the tube was also heated in flame after removing the cap. With a little of the agar medium, small amount of the culture was removed together with the fungi. Heat was applied to the neck of the tube again after which it was re-capped.

In order to drive out air that could be trapped between the hyphae, fungal materials were immersed in the drop of $70 \%$ alcohol and then eased out very gently with mounted needles. Both inoculating wire and needles were also sterilised after use by heating in the Bunsen flame. The fungal structures were stained with the lactophenol cotton blue dye preparation. The entire preparation was viewed under the microscope. Each derived anthraquinone compound was used to replace the lactophenol cotton blue and observed to determine its suitability as a stain.

\section{Results and Discussion}

From our previous finding (Ajayi and Olatunji, 2016), BRAM/p-iodoaniline inhibited Bacillus cereus and Pseudomonas aeruginosa significantly better than the standard antibiotics used as controls.

BRAM/p-iodoaniline perfectly showed the cell structures of the bacteria without any cell deformation, but it could not distinguish between gram positive and gram negative bacteria. BRAM/aniline was able to identify gram negative bacteria, with $60 \%$ capability in comparison to safranin. BRAM/acetylated PPD identified gram positive bacteria $(100 \%)$ as a primary stain and was a 
perfect alternative to crystal violet (Table 1). BRAM/ PAP was not good enough as a primary stain in the identification of gram positive bacteria but was a perfect alternative to LPCB in fungal identification. BRAM/otoluidine was a good counterstain to identify gram negative bacteria. BRAM/p-toluidine performed weakly as a counterstain $(40 \%)$. BRAM/m-toluidine was a perfect primary stain $(100 \%)$ for fungi as an alternative to methylene blue. BRAM/p-anisidine was able to stain the cells but performed weakly $(20 \%)$ as a counterstain. $\mathrm{BRAM} / \mathrm{m}$-anisidine and BRAM/PAP/p-TsCl showed an average staining performance $(50 \%)$ as primary stains in comparison to the standard. BRAM/Biaryl/PAP performed poorly and could not be used as a stain for either of the organisms. It can be observed that BRAM/otoluidine and BRAM/p-toluidine performed as counter stains while BRAM $/ \mathrm{m}$-toluidine functioned as a primary stain. This trend was also observed in the isomers of anisidine; BRAM/p-anisidine performed as a counterstain while BRAM $/ \mathrm{m}$-anisidine performed as a primary stain. The deduction made from this observation is that the para isomers have the capability to function as counter stains while their meta isomers functioned as primary stains.

Comparison of the standard stains with some of the derivatives. Crystal violet and BRAM/acetylated PPD. BRAM/acetylated PPD performed as a primary stain in addition to being a perfect alternative to Crystal violet in yeast identification. Figures 1-2 show the structures of these two dyes.

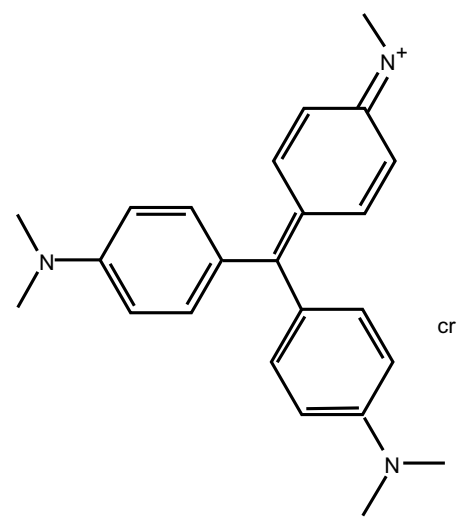

Fig. 1. Crystal violet

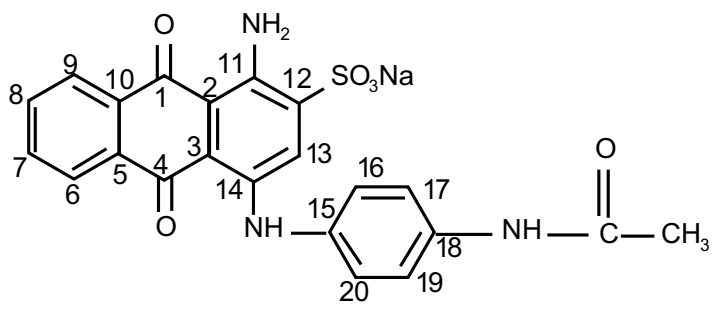

Fig. 2. BRAM/acetylated PPD

Table 1. Dye Staining Results of the Derivatives

\begin{tabular}{|c|c|c|c|c|c|}
\hline \multirow{3}{*}{ Compounds } & \multicolumn{4}{|c|}{ Microorganism } & \multirow[b]{3}{*}{ Comment } \\
\hline & \multirow{3}{*}{$\frac{\text { Primary }}{\text { Gram +ve }}$} & \multirow{2}{*}{$\frac{\text { Counter }}{\text { Gram -ve }}$} & \multicolumn{2}{|c|}{ Other type of stains } & \\
\hline & & & $\begin{array}{l}\text { Morphological } \\
\text { identification }\end{array}$ & $\begin{array}{l}\text { Fungal } \\
\text { stain }\end{array}$ & \\
\hline & & & (Yeast) & & \\
\hline BRAM/p-iodoaniline & & & & & Perfectly showed cell structures \\
\hline BRAM/aniline & & $60 \%$ & & & Can be used as a counterstain like Safranin \\
\hline $\mathrm{Bram} / \mathrm{BzCl} / \mathrm{PAP}$ & & $80 \%$ & & & $\begin{array}{l}\text { Alternative counterstain to distinguish } \\
\text { Gram positive bacteria. }\end{array}$ \\
\hline BRAM/acetylated PPD & $100 \%$ & & $90 \%$ & & Alternative to Crystal Violet \\
\hline BRAM/PAP & $60 \%$ & & & $100 \%$ & Alternative to Lactophenol Cotton blue \\
\hline BRAM/o-toluidine & & $90 \%$ & & & $\begin{array}{l}\text { Alternative counterstain to distinguish } \\
\text { Gram negative bacteria }\end{array}$ \\
\hline BRAM/p--toluidine & & $40 \%$ & & & $\begin{array}{l}\text { Weak but can be used as a counter stain to } \\
\text { distinguish Gram positive bacteria }\end{array}$ \\
\hline BRAM/m-toluidine & & & & $100 \%$ & Alternative to Methylene blue \\
\hline $\mathrm{BRAM} / \mathrm{p}$ - anisidine & & $20 \%$ & & & Perfectly stained the cells \\
\hline $\mathrm{BRAM} / \mathrm{m}$ - anisidine & $50 \%$ & & & & Primary stain \\
\hline $\mathrm{BRAM} / \mathrm{PAP} / \mathrm{p}-\mathrm{TsCl}$ & $50 \%$ & & & & Primary stain \\
\hline BRAM/Biaryl/PAP & & & & & Not Strong enough \\
\hline
\end{tabular}

Gram $+\mathrm{ve}=1$. Staphylococcus aureus; 2. Micrococcus luteus; Gram -ve = 1. Bacillus cereus, 2. Escheria coli, 3. Pseudomonas aeruginosa; = Yeast 1. Saccharomyces cerevisae, 2. Candida stellata; Fungi, 1. Penicillium italicum, 2. Aspergillus niger 
No striking similarity was observed in the structures of these two compounds; Crystal violet is triphenyl methane dye while BRAM/acetylated PPD is an anthraquinone dye yet the two showed similarities in their functionalities as antifungal and antibacterial agents (Table 2). BRAM/ acetylated PPD indicated very significant activity as much as the controls, exhibiting a very good staining activity. BRAM/acetylated PPD excelled in the famous gram stain procedure as a perfect alternative for crystal violet.

Table 2 illustrates the relationship between the antimicrobial activity of crystal violet and BRAM/ acetylated PPD. There are strong similarities in their staining activity and suitability for use in identification of gram positive bacteria and as a morphological yeast stain. BRAM/acetylated PPD also showed inhibitory activity on Escherichia coli.

Lactophenol cotton blue and BRAM/PAP. BRAM/ PAP could be used as an alternative to LPCB as a fungal stain. Figures 3-4 show the structures of the compounds.

Both BRAM/PAP and LPCB are anthraquinone compounds. BRAM/PAP had no antibacterial and antifungal properties as observed from the results of the tests in Tables 3-4.

Methylene blue and BRAM/m-toluidine. BRAM/mtoluidine exhibited a high inhibitory activity on Trichoderma viride. The inhibitory effect of this compound is the same as those of the controls; Ketoconazole and Miconazole. Methylene blue has been reported to inactivate Staphylococcus aureus (Zolfaghari et al., 2009).From our findings, BRAM/mtoluidine perfectly performed as a fungal stain and a

Table 2. Similarities in antimicrobial activity of primary dye stains

\begin{tabular}{|c|c|}
\hline Crystal Violet & BRAM/Acetylated PPD \\
\hline Dye stain for Gram positive bacteria & $\begin{array}{l}\text { Dye stain for Gram positive } \\
\text { bacteria }\end{array}$ \\
\hline Morphological yeast stain & Morphological yeast stain \\
\hline $\begin{array}{l}\text { Has antibacterial action against, } \\
\text { Escherichia coli, Staphylococcus } \\
\text { aureus, Streptococcus faecalis and } \\
\text { Bacillus subtilis (Adams, 1967) }\end{array}$ & $\begin{array}{l}\text { Inhibited Escherichia coli } \\
\text { better than Ciprofloxacin } \\
\text { (Ajayi and Olatunji, 2016) }\end{array}$ \\
\hline $\begin{array}{l}\text { Inhibits pathogenic fungi and } \\
\text { fungicidal against all types of }\end{array}$ & $\begin{array}{l}\text { Inhibited Trichoderma } \\
\text { viride as much as }\end{array}$ \\
\hline $\begin{array}{l}\text { Candida including Fluconazole } \\
\text { resistant species (Traboulsi, 2007, } \\
\text { Ying et al., 2010) }\end{array}$ & $\begin{array}{l}\text { Ketoconazole and } \\
\text { Miconazole (Ajayi and } \\
\text { Olatunji, 2016) }\end{array}$ \\
\hline
\end{tabular}

good alternative to methylene blue. Figures 5-6 show the structures of these compounds.

$\boldsymbol{B R} \boldsymbol{A M} / \boldsymbol{B} \boldsymbol{z} \boldsymbol{C l} / \boldsymbol{P} \boldsymbol{A P}$. BRAM/BzCl/PAP performed excellently well as an antibacterial agent and had some inhibitory effect as an antifungal agent. It also showed a very good activity as a primary stain in identifying gram positive bacteria (Fig. 7).<smiles>O=c1c2ccccc2c(=O)c2c1ccc1[nH]c3c(ccc4c(=O)c5ccccc5c(=O)c43)[nH]c12</smiles>

Fig. 3. Lactophenol cotton blue (LPCB)<smiles>NC(=O)C1=C(N)C2C(=O)c3ccccc3C(=O)C2C(Nc2ccc(O)cc2)=C1</smiles>

Fig. 4. BRAM/PAP<smiles>CN(Cl)c1ccc2nc3ccc(=[N+](C)C)cc-3sc2c1</smiles>

Fig. 5. Methylene Blue<smiles>Cc1cccc(Nc2cc(S(N)(=O)=O)c(N)c3c2C(=O)c2ccccc2C3=O)c1</smiles>

Fig. 6. BRAM $/ \mathrm{m}$-Toluidine 
Table 3. Antibacterial activity of the additional derivatives

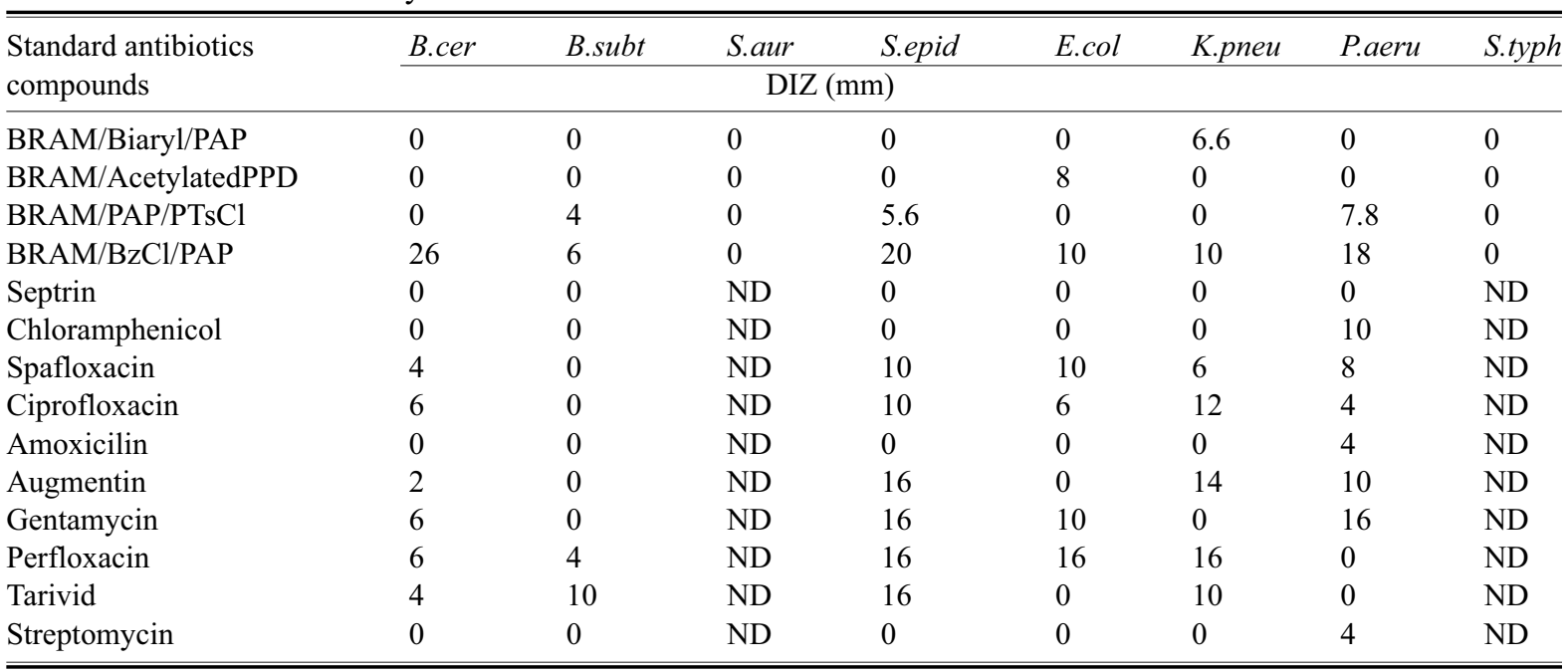

$\mathrm{DIZ}=$ Diameter of inhibition zone $(\mathrm{mm})$; ND- Not determined; Used concentration: $1 \mathrm{mg}$ of each sample was dissolved in $1 \mathrm{~mL}$ of methanol. The experiments were carried out in triplicate and results expressed as mean values.

Table 4. Antifungal activity of derivatives

\begin{tabular}{llllll}
\hline \hline compounds & $\begin{array}{l}\text { Trichoderma } \\
\text { viride }\end{array}$ & $\begin{array}{l}\text { Aspergillus } \\
\text { flavus }\end{array}$ & $\begin{array}{l}\text { Aspergillus } \\
\text { niger }\end{array}$ & $\begin{array}{l}\text { Fusarium } \\
\text { oxysporium }\end{array}$ & $\begin{array}{l}\text { Fusarium } \\
\text { compacticus }\end{array}$ \\
\cline { 2 - 6 } & \multicolumn{2}{c}{ DIZ(mm) } & ND & ND \\
\hline Ketoconazole & 18 & ND & ND & ND & ND \\
Miconazole & 18 & ND & 0 & 0 & 0 \\
BRAM/PAP & 0 & 0 & 0 & 0 & 0 \\
BRAM/m-toluidine & 18 & 0 & 0 & 0 & 0 \\
BRAM/o-toluidine & 4 & 0 & 0 & 0 & 0 \\
BRAM/p-toluidine & 6 & 0 & 0 & 0 & 0 \\
BRAM/m-anisidine & 12.2 & 0 & 0 & 0 & 0 \\
BRAM/p-anisidine & 0 & 0 & 0 & 0 & 0 \\
BRAM/p-iodoaniline & 2.2 & 0 & 0 & 0 & 0 \\
BRAM/aniline & 0 & 0 & 0 & 0 & 0 \\
BRAM/Biaryl/PAP & 6 & 0 & 0 & 0 & 0 \\
BRAM/acetylatedPPD & 18 & 0 & 0 & 0 & 0 \\
BRAM/PAP/p-TsCl & 0 & 0 & 0 & 0 & 0 \\
BRAM/BzCl/PAP & 10.5 & 0 & 0 & 0 \\
\hline \hline
\end{tabular}

DIZ=Diameter of inhibition zone (mm); ND- Not determined; Experiments were done in triplicate and results are mean values. Used concentration: $1 \mathrm{mg}$ of each sample was dissolved in $1 \mathrm{~mL}$ of methanol.

We were able to make the following deductions from this study; from the results of the antibacterial test, BRAM/PAP performed excellently, inhibiting Bacillus cereus, Staphylococcus aureus and Pseudomonas aeruginosa much more than the standard antibiotics. It was also observed that in the staining test, $\mathrm{BRAM} / \mathrm{BzCl} / \mathrm{PAP}$ showed very good staining quality as a primary stain and could be used as an alternative counterstain to distinguish gram positive bacteria. The antifungal test showed BRAM/Acetylated PPD and<smiles>CS(=O)(=O)c1cc(Nc2ccc(OCc3ccccc3)cc2)c2c(c1N)C(=O)c1ccccc1C2=O</smiles>

Fig. 7. $\mathrm{BRAM} / \mathrm{BzCl} / \mathrm{PAP}$. 
BRAM/m-toluidine had as much inhibitory effect on Trichoderma viride as ketoconazole and miconazole. BRAM/Acetylated PPD also exhibited excellent staining activity as a primary stain for gram positive bacteria and as a morphological stain in yeast identification. The results of the staining test show that this compound could be used as an alternative to crystal violet. $\mathrm{BRAM} / \mathrm{m}$-toluidine was able to stain the fungal cells effectively as much as methylene blue. We inferred from these results that the compounds with high antibacterial and antifungal activity also showed great staining activity.

\section{Conclusion}

BRAM/m-toluidine stained Penicillium italicum and Aspergillus niger as effectively as methylene blue. BRAM/acetylated PPD perfectly stained Staphylococcus aereus and Micrococcus luteus. BRAM/PAP performed well as a good substitute for LPCB in the identification of Penicillium italicum and Aspergilus niger. The staining tests carried out on the compounds show that they are viable alternatives to existing dyes currently used in bacterial and fungal identification. Many of the existing dyes used in staining have tremendous commercial value due to wide usage. From this study we have been able to deduce that there is indeed correlation between antimicrobial and staining activity of these anthraquinone dye derivatives.

Conflict of Interest. The authors declare no conflict of interest

\section{References}

Adams, E. 1967. The antibacterial action of crystal violet, Journal of Pharmacy and Pharmacology, 19: 821-826.

Ajayi, O.A., Olatunji, G.A. 2016. Synthesis, characterization and antibacterial activity of some anthraquinone dye derivatives. Journal of Baic and Applied Research International, 17: 280-289.

Baqi, Y., Weyler, S., Iqbal, J., Zimmermann, H., Muller, C. 2008. Structure- activity relationships of anthraquinone derivatives derived from bromaminic acid as inhibitors of ectonucleoside triphosphate diphosphohydrolases (E-NTPDases). Org Lett, 5: 91-106.
Bauer, A.W., Kirby, M.M., Sherris, J.C., Truck, M. 1966. Antibiotic susceptibility testing by a standard single disc method. American Journal Clinical Pathology, 45: 493-496.

Booth, G., Zollinger, H., McLaren, K., Sharples, W.G., Westwell, A. 2000. Dyes, General Survey. In: Ullmann's Encyclopedia of Industrial Chemistry, pp. 289-296, Wiley-VCH, Verlag, Germany.

Cheesbrough, M. 2004. District Laboratory Practice in Tropical Countries (Part 2). pp. 299-329, Cambridge University Press, Cambridge, UK.

Chengaiah, B., Mallikarjima, R.K., Kumar., M.K., Alagusundaram, M., Madhusudhana, C.C. 1997. Medicinal importance of natural dyes. A Review. International Journal of Pharm Tech Research, 2: 144-154.

Derwich, E., Benzianne, Z., Boukir, A. 2010. Antibacterial activity and chemical composition of the leaf essential oil of Mentha rotundifolia from Morocco. Electronic Journal of Environmental, Agricultural and Food Chemistry, 9: 415-423.

Hussein, S.A.M., Barakat, H.H., Merfort, I., Nawwar, M.A.M. 1997. Tannins from the leaves of Punica granatum. Phytochemistry, 45: 819-823.

Iscan, G., Demirci, F., Kirimer, N., Kurkcuoglu, M., Baser, K. 2002. Antimicrobial Screening: Mentha piperita essential oil. Journal of Agriculture and Food Chemistry, 50: 3942-3946.

Peralta-Sánchez, J.M., Soler, J.J., Martín-Platero, A.M., Knight, R., Martínez-Bueno, M., Møller, A.P. 2013. Eggshell bacterial load is related to antimicrobial properties of feathers lining barn swallow nests. Microbiology Ecology, 67: 480-487.

Traboulsi, R.S., Mukherjee, P.K., Chandra, J., Salata, R.A., Jurevic, R., Ghannoum, M. 2011. Gentian violet exhibits activity against biofilms formed by oral Candida isolates obtained from HIV-infected patients. Antimicrobial Agents and Chemotherapy, 55: 3043-3045.

Ying, S., Qing, S., Chunyang, L.2010. The effect of gentian violet on virulent properties of Candida albicans. Mycopathologia, 169: 279-285.

Zolfaghari, P.S., Packer, S., Singer, M., Nair, S.P., Bennett, J., Street, C., Wilson, M. 2009. In vivo killing of Staphylococcus aureus using a lightactivated antimicrobial agent". BMC Microbiology, 9: 27 . 